\title{
Influence of Donor Blood Temperature on Metabolic and Hormonal Changes During Exchange Transfusion
}

\author{
R. D. G. MILNER, M. FEKETE, J. S. HODGE, and R. ASSAN \\ From the Departments of Child Health and Chemical Pathology, University of Manchester; and the Faculté de Médecine, \\ Paris
}

\begin{abstract}
Milner, R. D. G., Fekete, M., Hodge, J. S., and Assan, R. (1972). Archives of Disease in Childhood, 47, 933 . Influence of donor blood temperature on metabolic and hormonal changes during exchange transfusion. Measurements of plasma glucose, free fatty acid, glycerol, insulin, growth hormone, and glucagon were made during exchange transfusions performed with blood heated to 36.5 to $38.5{ }^{\circ} \mathrm{C}$ or cooled to 10 to $13^{\circ} \mathrm{C}$. Term, normally grown infants suffering from rhesus incompatibility were studied. 10 received warm transfusions and 9 cold transfusions. Cold transfusions caused a progressive fall in rectal, umbilical vein, and skin temperature, whereas warm transfusions caused little change in body temperature. Infants receiving cold transfusions had a greater net positive balance of glucose and a smaller net negative balance of free fatty acids than those receiving warm transfusions. Other metabolic and hormonal responses to exchange transfusion were similar in the two groups.

It was concluded that while exchange transfusion performed with cold blood did cause thermal stress to the infant, the metabolic consequences were slight and were mitigated by the glucose in the donor blood. There was no evidence that insulin, growth hormone, or glucagon played a part in the response of the newborn infant to cold.
\end{abstract}

Exchange transfusion still carries an appreciable mortality (Boggs and Westphal, 1960; Weldon and Odell, 1968). Among the factors that are potentially harmful to the baby are the profound metabolic changes caused by the donor blood which differs from that of the infant in its biochemical composition, acidity, and temperature (Anderson et al., 1963; Povey, 1964; Calladine et al., 1965; Varga and Hutas, 1966). Our interest in the use of exchange transfusion to study the effects of donor blood temperature on the thermal, metabolic, and hormonal response of the newborn infant stemmed from the work of Hey, Kohlinsky, and O'Connell (1969). These workers observed that during exchange transfusion of infants with blood at room temperature there was an increase in oxygen consumption and a fall in deep body temperature, both of which remained normal when the donor blood was warmed to $37^{\circ} \mathrm{C}$. Since exchange transfusions had been used previously to

Received 14 April 1972. study metabolic and hormonal interrelation (Milner et al., 1972), the work was extended to investigate the metabolic and hormonal response to the cold stress imposed by transfusion with blood at room temperature.

\section{Patients and Methods}

Patients. 21 exchange transfusions were performed on 20 term newborn infants who were of normal birthweight for their gestational age. One infant had two transfusions but the interval between the first and the second transfusion was more than 48 hours. All transfusions were performed because of mild to moderate erythroblastosis fetalis due to rhesus incompatibility. In all cases pregnancy was uneventful. Delivery was normal in all but two cases in which the infant was delivered by caesarean section or forceps because of fetal distress. One infant required resuscitation but responded well. The Coombs reaction was always positive in the cord blood. The donor blood was warmed for 10 transfusions and cooled for 11 transfusions. The main clinical and technical characteristics of the two groups of infants and transfusions are presented in Table $\mathbf{I}$. 
TABLE I

Details of Clinical Status of Infants and Exchange Transfusion Technique

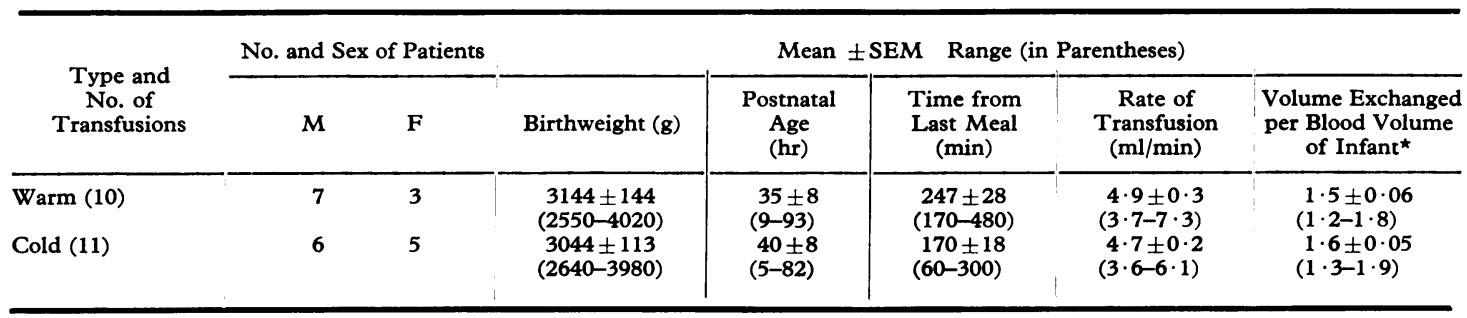

$\star$ Calculated as blood volume exchanged $(\mathrm{ml}) \div($ weight of infant $(\mathrm{kg}) \times 85)$.

Transfusion technique. All transfusions were performed in a room heated to 24 to $25^{\circ} \mathrm{C}$. The infants were transfused lying on an 'Infant Warmer' (Air Shields), the surface temperature of which was kept between 32 and $35^{\circ} \mathrm{C}$. The skin temperature of the right midaxillary region was measured continuously by a thermistor thermometer (Air Shields). The donor blood passed from the bottle through a $180 \mathrm{~cm}$ plastic giving set to a $700 \mathrm{~cm}$ plastic coil of $4 \mathrm{~mm}$ internal diameter (Hem-O-Grad blood warming coil) which was immersed in a water bath. The temperature of the water was 36.5 to $38.5^{\circ} \mathrm{C}$ or 10 to $13^{\circ} \mathrm{C}$. Blood passed from the coil to a syringe and umbilical venous catheter via a four-way tap. The distance from the water bath to the baby was never more than $40 \mathrm{~cm}$. The umbilical venous catheter was inserted the minimum distance compatible with the easy withdrawal of blood, usually 5 to $7 \mathrm{~cm}$, and the transfusion was carried out using $20 \mathrm{ml}$ volumes of blood. In 2 cases umbilical venous catheters were used which had thermistors mounted at the tip so that a continuous record could be made of the temperature of blood passing through the catheter (Rawcliffe and Highfield, 1973). In these infants the deep rectal and skin temperatures were also measured with thermistors.

Laboratory methods. The donor blood was never more than 72 hours old and was preserved with acidcitrate and dextrose $(2.0 \mathrm{~g}$ disodium citrate and $3.0 \mathrm{~g}$ dextrose dissolved in $120 \mathrm{ml}$ water in each $540 \mathrm{ml}$ bottle). Supernatant fluid was removed from the donor blood to produce a final haematocrit of 55 to $60 \%$. Blood specimens were collected and stored as described previously (Milner et al., 1972).

Plasma glucose was determined using glucose oxidase (Trinder, 1969). Free fatty acids (FFA) were measured by the method of Duncombe (1964), and glycerol according to Eggstein and Kreutz (1966) using reagents from Boehringer, Mannheim GMBH. Plasma insulin was measured by immunoassay (Hales and Randle, 1963) using a human insulin standard (MRC preparation 66/304). Plasma growth hormone (GH) was measured similarly using a human growth hormone standard (MRC preparation 66/217). Plasma glucagon was measured by the method of Assan, Tchobroutsky, and Derot (1971) using a pork glucagon standard (kindly given by Dr. Bouchet of Novo, Paris) and an antibody to glucagon-like immunoreactive material which crossreacted weakly with gut glucagon.

Calculations. The mean plasma concentrations and the net balance of hormones and metabolites injected into and removed from the infant were calculated as described previously (Milner et al., 1972).

\section{Results}

Temperature (Table II). The most complete records of the thermal consequences of exchange transfusion with warm or cold blood were obtained in the two transfusions where it was possible to monitor temperature continuously. In the warm transfusion (Fig. 1), the temperature of the blood withdrawn from the infant remained constant and that of the blood injected was about $1^{\circ} \mathrm{C}$ less and fluctuated little. During the transfusion the rectal temperature rose from $36.4{ }^{\circ} \mathrm{C}$ to $36.9{ }^{\circ} \mathrm{C}$, and the skin temperature rose from $34.8{ }^{\circ} \mathrm{C}$ to $35.8{ }^{\circ} \mathrm{C}$. The most important difference between the cold and warm transfusion was the temperature of the injected blood (Fig. 2). The temperature in the umbilical vein was recorded by a thermistor bead located adjacent to the proximal hole in the catheter tip. The temperature in the vein fell as each $20 \mathrm{ml}$ donor blood was injected and the rate of fall was noted to increase with the speed of injection of donor blood. The irregularities of temperature in the record were likely therefore to be as much a product of the rate of transfusion as of the temperature of the donor blood. During the cold transfusion there was a gradual progressive fall in the skin temperature, rectal temperature, and temperature of blood withdrawn from the baby (apices of the saw-tooth umbilical venous temperature record).

The opportunity to make detailed temperature records (Fig. 1 and 2) came at the end of the study and therefore the inadequacy of cooling donor blood to 10 to $13^{\circ} \mathrm{C}$ was appreciated retrospectively. 


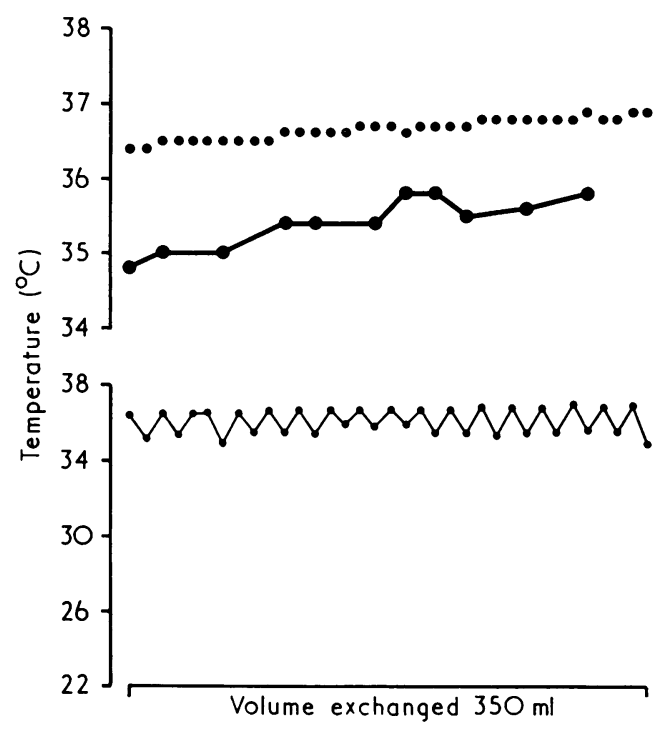

FIG. 1.-Temperature records during an exchange transfusion in which the donor blood was warmed to $36 \cdot 5$ to $38.5^{\circ} \mathrm{C}$. The upper discontinuous record is rectal temperature. The centre record is of right midaxillary skin temperature. The lower record is of temperature in the umbilical vein before and after each injection of $20 \mathrm{ml}$ donor blood.

TABLE II

Temperature Changes During Exchange Transfusion with Warm or Cold Blood

\begin{tabular}{l|c|c}
\hline \multirow{1}{*}{ Temperature of: } & Mean \pm SEM Temperature $\left({ }^{\circ} \mathrm{C}\right)$ \\
\cline { 2 - 3 } & $\begin{array}{c}\text { Warm } \\
\text { Transfusions (10) }\end{array}$ & $\begin{array}{c}\text { Cold } \\
\text { Transfusions (11) }\end{array}$ \\
\hline Water bath & $37 \cdot 2 \pm 0 \cdot 2$ & $11 \cdot 6 \pm 0 \cdot 4$ \\
Surface of infant warmer & $33 \cdot 0 \pm 0 \cdot 4$ & $33 \cdot 3 \pm 0 \cdot 3$ \\
Infant's skin & $35 \cdot 6 \pm 0 \cdot 1$ & $36 \cdot 1 \pm 0 \cdot 1$ \\
$\quad$ Start of transfusion & $35 \cdot 9 \pm 0 \cdot 2$ & $35 \cdot 8 \pm 0 \cdot 1$ \\
Middle of transfusion & $36 \cdot 1 \pm 0 \cdot 2$ & $35 \cdot 6 \pm 0 \cdot 2$ \\
End of transfusion & $35 \cdot 6 \pm 0$ \\
\hline
\end{tabular}

Since the two transfusions with detailed temperature records were carried out under precisely the same conditions as the remainder of the warm and cold transfusions they were accepted as illustrating the temperature changes occurring in each group. In 8 of the 11 cold transfusions a progressive fall in skin temperature was observed. The skin temperature in the 10 infants receiving warm transfusions was on average $0.5{ }^{\circ} \mathrm{C}$ higher at the end of transfusion but the change was not significant. The detailed temperature records were similar to those reported by Hey et al. (1969) and indicated

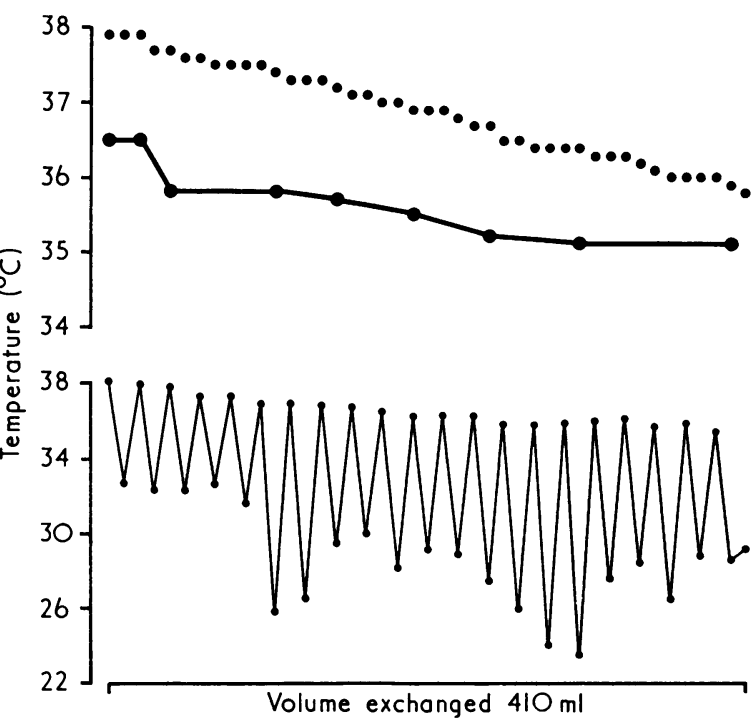

FIG. 2.-Temperature records during an exchange transfusion in which the donor blood was cooled to 10 to $13^{\circ} \mathrm{C}$. Key as in Fig. 1.

that increased oxygen consumption probably occurred in the infants in the present study who received cold transfusions.

Plasma concentrations of metabolites and hormones. The mean plasma concentration of all metabolites and hormones measured was similar in the donor blood with the exception of plasma glucose, which was fortuitously higher in the blood used for cold transfusions. In the infants before the transfusion started there was a significant difference only in plasma GH which was higher in the group which was transfused with cold blood. A comparison of the metabolites and hormones in the donor blood with those in the infant before transfusion started revealed in both groups that the mean donor plasma glucose was significantly higher than that in the infants $(P<0.001)$, whereas the levels of glucagon, $\mathrm{GH}$, and FFA were significantly higher in the infants than in the donor blood $(P<0.01)$. The plasma glycerol in the infants was twice that in the donor blood, but due to variation between babies the difference between the mean levels was not significant.

Similar changes in plasma concentrations of metabolites and hormones occurred during exchange transfusion with warm or cold blood (Table III). There was a highly significant rise in plasma glucose during the transfusion $(P<0.001)$ accompanied by a significant rise in plasma insulin 
TABLE III

Plasma Metabolite and Hormone Concentrations During Exchange Transfusions with Warm or Cold Blood

\begin{tabular}{|c|c|c|c|c|c|c|}
\hline \multirow{2}{*}{ Metabolite or Hormone } & \multicolumn{6}{|c|}{ Mean \pm SEM Plasma Concentration During Transfusion (No. of Observations in Parentheses) } \\
\hline & Donor & $0 \mathrm{ml}$ & $100 \mathrm{ml}$ & $200 \mathrm{ml}$ & $300 \mathrm{ml}$ & $400 \mathrm{ml}$ \\
\hline $\begin{array}{l}\text { Warm transfusions } \\
\text { Glucose }(\mathrm{mg} / 100 \mathrm{ml}) \\
\text { FFA }(\mu \mathrm{mol} / 1 .) \\
\text { Glycerol }(\mu \mathrm{mol} / 1 .) \\
\text { Insulin }(\mu \mathrm{U} / \mathrm{ml}) \\
\text { Glucagon }(\mathrm{pg} / \mathrm{ml}) \\
\text { GH }(\mathrm{ng} / \mathrm{ml})\end{array}$ & $\begin{array}{c}386 \pm 35(10)^{\star} \\
302 \pm 47(10) \\
63 \pm 11(10) \\
37 \pm 6(10) \\
282 \pm 29(10) \\
3 \cdot 0 \pm 0 \cdot 7(10)\end{array}$ & $\begin{aligned} 75 & \pm 4(10) \\
1299 & \pm 155(10) \\
114 & \pm 23(10) \\
34 & \pm 6(10) \\
513 & \pm 80(10) \\
29 & \pm 4(10)^{\star}\end{aligned}$ & $\begin{array}{c}120 \pm 3(10)^{\star} \\
983 \pm 80(10)^{\star} \\
94 \pm 17(10) \\
64 \pm 17(10) \\
433 \pm 66(10) \\
45 \pm 8(10)\end{array}$ & $\begin{array}{l}139 \pm 4(10) \\
817 \pm 72(10) \dagger \\
91 \pm 15(10) \\
63 \pm 10(10) \\
423 \pm 62(10) \\
58 \pm 9(10)\end{array}$ & $\begin{array}{rl}153 & \pm 8(10) \\
596 \pm 70(10) & \pm 19(10) \\
97 \pm 19 & 74 \pm 17(10) \\
410 \pm 54(10) \\
84 \pm 16(10)\end{array}$ & $\begin{array}{r}157 \pm 14(8) \\
503 \pm 70(8) \\
88 \pm 21(8) \\
81 \pm 15(8) \\
377 \pm 36(8) \\
94 \pm 31(8)\end{array}$ \\
\hline $\begin{array}{l}\text { Cold transfusions } \\
\text { Glucose }(\mathrm{mg} / 100 \mathrm{ml}) \\
\text { FFA }(\mu \mathrm{mol} / \mathrm{l} .) \\
\text { Glycerol }(\mu \mathrm{mol} / 1 .) \\
\text { Insulin }(\mu \mathrm{U} / \mathrm{ml}) \\
\text { Glucagon }(\mathrm{pg} / \mathrm{ml}) \\
\text { GH }(\mathrm{ng} / \mathrm{ml})\end{array}$ & $\begin{array}{c}521 \pm 31(11) \\
277 \pm 40(11) \\
67 \pm 7(8) \\
29 \pm 3(11) \\
309 \pm 14(8) \\
2 \cdot 0 \pm 0 \cdot 3(11)\end{array}$ & $\begin{aligned} 82 & \pm 4(11) \\
1007 & \pm 138(11) \\
124 & \pm 30(8) \\
31 & \pm 4(11) \\
804 & \pm 172(8) \\
49 & \pm 4(11)\end{aligned}$ & $\begin{array}{c}133 \pm 3(11) \\
699 \pm 68(11) \\
94 \pm 21(8) \\
69 \pm 15(11) \\
628 \pm 81(8) \\
45 \pm 5(11)\end{array}$ & $\begin{array}{c}150 \pm 6(11) \\
520 \pm 56(11) \\
85 \pm 19(8) \\
67 \pm 10(11) \\
564 \pm 67(8) \\
57 \pm 7(11)\end{array}$ & $\begin{aligned} 165 & \pm 6(11) \\
458 & \pm 51(11) \\
78 & \pm 18(8) \\
64 & \pm 10(11) \\
541 & \pm 4(8) \\
62 & \pm 10(11)\end{aligned}$ & $\begin{array}{c}172 \pm 9(10) \\
396 \pm 37(10) \\
84 \pm 10(7) \\
83 \pm 9(10) \\
517 \pm 102(7) \\
69 \pm 16(10)\end{array}$ \\
\hline
\end{tabular}

Level of statistical significance for comparison of warm and cold transfusions: ${ }^{\star} P<0.05,+P<0.005$.

$(P<0.01)$ and a fall in plasma FFA $(P<0.001)$ and glucagon levels $(P<0.05)$. There was no significant difference in the overall changes in plasma concentration of glucose, FFA, insulin, or glucagon between the two groups. Plasma GH levels rose significantly $(P<0.05)$ during warm transfusions but though a mean rise of $20 \mathrm{ng} / \mathrm{ml}$ occurred in cold transfusions the change was not significant due to variation between infants.

In both warm and cold transfusions there was a net positive balance of glucose and negative balance of all other metabolites and hormones measured (Table IV). The size of the net balance was similar for GH, glucagon, and insulin. The net loss of glycerol was less in the cold than the warm transfusions but the difference was not significant. In cold transfusions, the positive balance of glucose was nearly twice that in warm transfusions $(P<0.005)$ and the negative balance of FFA was $60 \%$ that found in warm transfusions $(P<0 \cdot 05)$.

\section{Discussion}

In the attempt to make the infants receiving warm or cold transfusions comparable, great care was taken to standardize the technique and conditions of transfusion. Within the constraints imposed by clinical investigation the two groups of infants were similar. All were term, normallygrown babies suffering from haemolytic disease due to rhesus incompatibility. Variation occurred among infants in the age at which transfusion was performed and the interval between the last meal and the start of transfusion, but the mean values of these variables were similar in the two groups.

The striking finding in the study of plasma metabolites and hormones was the great similarity between the two groups. The mean plasma concentration of all substances measured in the donor blood was similar with the exception of glucose. Despite the higher mean concentration of glucose in the donor blood used in cold transfusions, there

TABLE IV

Total Amount of Metabolite or Hormone Infused or Removed in Warm or Cold Transfusions

\begin{tabular}{|c|c|c|c|c|c|c|}
\hline \multirow{3}{*}{ Hormone or Metabolite } & \multicolumn{6}{|c|}{ Mean \pm SEM Amount Infused or Removed/kg Body Weight } \\
\hline & \multicolumn{3}{|c|}{ Warm Transfusions } & \multicolumn{3}{|c|}{ Cold Transfusions } \\
\hline & In & Out & Balance & In & Out & Balance \\
\hline $\begin{array}{l}\text { Glucose (mg) } \\
\text { FFA ( } \mu \mathrm{mol}) \\
\text { Glycerol ( } \mu \mathrm{mol}) \\
\text { Insulin (mU) } \\
\text { Glucagon (ng) } \\
\text { GH }(\mu \mathrm{g})\end{array}$ & $\begin{array}{c}217 \pm 22 \\
16 \cdot 9 \pm 2 \cdot 6 \\
3 \cdot 7 \pm 0 \cdot 8 \\
1 \cdot 9 \pm 0 \cdot 4 \\
16 \cdot 4 \pm 2 \cdot 1 \\
0 \cdot 21 \pm 0 \cdot 05\end{array}$ & $\begin{array}{c}100 \pm 7 \\
61 \cdot 6 \pm 6 \cdot 8 \\
7 \cdot 0 \pm 1 \cdot 0 \\
4 \cdot 3 \pm 0 \cdot 7 \\
29 \cdot 2 \pm 4 \cdot 4 \\
4 \cdot 57 \pm 0 \cdot 68\end{array}$ & $\begin{array}{r}+117 \pm 19 \\
-44 \cdot 7 \pm 6 \cdot 4 \\
-3 \cdot 2 \pm 1 \cdot 2 \\
-2 \cdot 2 \pm 0 \cdot 9 \\
-12 \cdot 7 \pm 3 \cdot 6 \\
-4 \cdot 36 \pm 0 \cdot 69\end{array}$ & $\begin{array}{c}332 \pm 21 \\
17 \cdot 5 \pm 2 \cdot 6 \\
4 \cdot 1 \pm 0 \cdot 4 \\
2 \cdot 0 \pm 0 \cdot 3 \\
21 \cdot 8 \pm 1 \cdot 6 \\
0 \cdot 15 \pm 0 \cdot 03\end{array}$ & $\begin{array}{c}110 \pm 6 \\
45 \cdot 1 \pm 4 \cdot 9 \\
6 \cdot 7 \pm 1 \cdot 2 \\
4 \cdot 3 \pm 0 \cdot 5 \\
44 \cdot 7 \pm 5 \cdot 3 \\
3 \cdot 81 \pm 0 \cdot 52\end{array}$ & $\begin{array}{c}+222 \pm 19 \star \\
-27 \cdot 6 \pm 5 \cdot 2 \dagger \\
-2 \cdot 6 \pm 1 \cdot 4 \\
-2 \cdot 3 \pm 0 \cdot 5 \\
-22 \cdot 9 \pm 5 \cdot 2 \\
-3 \cdot 66 \pm 0.51\end{array}$ \\
\hline
\end{tabular}

Level of significance of a difference in the net balance between warm and cold transfusions: $\star P<0 \cdot 05,+P<0 \cdot 005$. 
was little difference in the rise of plasma glucose during the course of the transfusion between the two groups. Similar changes in plasma concentration between the $0 \mathrm{ml}$ and $400 \mathrm{ml}$ sample occurred in both groups for FFA, glycerol, and insulin. The mean \pm SEM rise in plasma $G H$ was $68 \pm 26 \mathrm{ng} / \mathrm{ml}$ in the warm transfusions and $25 \pm 13 \mathrm{ng} / \mathrm{ml}$ in the cold transfusions. The difference was not significant, but in view of the similar net balances of $\mathrm{GH}$ in the two types of transfusion the question of whether donor blood temperature influences GH secretion in the newborn must remain open. The mean \pm SEM fall in plasma glucagon in the cold transfusions was $257 \pm 89 \mathrm{pg} / \mathrm{ml}$ and $117 \pm 50 \mathrm{pg} / \mathrm{ml}$ in the warm transfusions. The net negative balance of glucagon in the cold transfusions was greater than in the warm transfusions. The changes in both glucagon plasma levels and net balance could be explained by the fact that the initial plasma level in the infants receiving cold transfusions was greater than that in those receiving warm transfusions.

Despite the similar change in plasma glucose levels in the two groups and the fact that the infants receiving cold transfusions had on average $53 \%$ more glucose infused than those receiving warm transfusions, the net positive balance of glucose was significantly greater in the group having cold transfusions. The negative balance of FFA in this group was significantly less than that in the infants having warm transfusions, though both groups had similar amounts of FFA infused and similar changes in plasma FFA concentration. These observations could be interpreted tentatively as evidence that FFA and glucose are fuels of importance in the metabolic response to cold stress.

The findings in the present study complement those of Fekete et al. (1972) which indicated that insulin, GH, and glucagon did not play important roles in the response of the human newborn infant to cold stress. Further they show that though exchange transfusion with blood at room temperature constitutes a cold stress, the metabolic response of the infant is aided by the intermittent infusion of glucose which is part of the preservative for the donor blood. The heating of donor blood to $37^{\circ} \mathrm{C}$ is advantageous in that it removes the thermal stress. Against this advantage have to be set the potential disadvantages that accompany the increased complexity of an already complicated set of procedures. These include the risk of overheating the donor blood, and the risk of entraining water into the donor blood coil immersed in the water bath. Other factors, such as the possibility of elution of chemicals by the donor blood from the plastic warming coil, remain to be studied. On balance, the warming of donor blood for exchange transfusion to body temperature is desirable provided that it is carried out with careful supervision. Exchange transfusion with blood at room temperature does constitute a cold stress, but one which appears to have few metabolic consequences.

We are grateful to Professor J. A. Davis for his encouragement. Financial support was given by the Medical Research Council and the Research Grants Committee of the United Manchester Hospitals. M.F. was in receipt of a Wellcome Clinical Research Fellowship.

\section{REFERENCES}

Anderson, J., Marks, V., Tomlinson, R. W. S., and Walker, W. (1963). Changes in the blood concentration of glucose, alphaoxyglutarate, pyruvate and citrate during exchange transfusion in haemolytic disease of the newborn. Archives of Disease in Childhood, 38, 481.

Assan, R., Tchobroutsky, G., and Derot, M. (1971). Glucagon radioimmunoassay: technical problems and recent data. In Immunological Methods in Endocrinology, Symposium in Ulm 1970, p. 82. Hormone and Metabolic Research, Supplement Series No. 3. Ed. by K. Federlin, C. N. Hales, and J. Kracht. Thieme, Stuttgart.

Boggs, T. R., and Westphal, M. C. (1960). Mortality of exchange transfusion. Pediatrics, 26, 745.

Calladine, M., Gairdner, D., Naidoo, B. T., and Orrell, D. H. (1965). Acid-base changes following exchange transfusion with citrated blood. Archives of Disease in Childhood, 40, 626.

Duncombe, W. G. (1964). The colorimetric microdetermination of non-esterified fatty acids in plasma. Clinica Chimica Acta, 9, 122.

Eggstein, M., and Kreutz, F. H. (1966). Eine neue Bestimmung der Neutralfette im Blutserum und Gewebe. I. Prinzip, Durchführung und Besprechung der Methode. Klinische Wochenschrift, 44, 262.

Fekete, M., Milner, R. D. G., Soltész, Gy., Assan, R., and Mestyán, J. (1972). Plasma glucagon, thyrotropin, growth hormone and insulin response to cold exposure in the human newborn. Acta Paediatrica Scandinavica, 61, 435.

Hales, C. N., and Randle, P. J. (1963). Immunoassay of insulin with insulin-antibody precipitate. Biochemical fournal, 88, 137.

Hey, E. N., Kohlinsky, S., and O'Connell, B. (1969). Heat losses from babies during exchange transfusion. Lancet, 1, 335.

Milner, R. D. G., Fekete, M., Assan, R., and Hodge, J. S. (1972). Effect of glucose on plasma glucagon, growth hormone, and insulin in exchange transfusion. Archives of Disease in Childhood, 47, 179.

Povey, M. J. C. (1964), pH changes during exchange transfusion. Lancet, 2, 339 .

Rawcliffe, J., and Highfield, A. B. (1973). A sensitive catheter thermometer for medical use. Fournal of Scientific Instruments. (Submitted for publication.)

Trinder, P. (1969). Determination of glucose in blood using glucose oxidase with an alternative oxygen acceptor. Annals of Clinical Biochemistry, 6, 24.

Varga, F., and Hutas, S. (1966). Alteration in blood pH and acidbase parameters during exchange transfusion in the newborn. Biologia Neonatorum, 10, 55.

Weldon, V. V., and Odell, G. B. (1968). Mortality risk of exchange transfusion. Pediatrics, 41, 797.

Correspondence to Dr. R. D. G. Milner, Department of Child Health, St. Mary's Hospital, Hathersage Road, Manchester M13 0JH. 